\title{
Prediction of Efficiency of an Existing 14-speed Bicycle Internal Drive Hub
}

\author{
Yi-Chang Wu*, Li-An Chen, Che-Wei Chang \\ Department of Mechanical Engineering, National Yunlin University of Science \& Technology, Taiwan \\ * Corresponding Author: wuyc@yuntech.edu.tw
}

Copyright $@ 2014$ Horizon Research Publishing All rights reserved.

\begin{abstract}
This paper presents an analytical process for predicting the mechanical efficiency of bicycle internal drive hubs composed of planetary gear mechanisms. An existing 14-speed internal drive hub is introduced and is taken as an example to demonstrate the analytical process. Kinematic analysis, static torque analysis, power flow analysis and mechanical efficiency analysis of this internal drive hub are illustrated by applying the fundamental circuit method.
\end{abstract}

Keywords Mechanical Efficiency, 14-speed Internal Drive Hub, Bicycle

\section{Introduction}

An internal drive hub is a mechanical speed-changing device installed inside the hub shell of the rear wheel of a bicycle. The internal drive hub system is more reliable than the derailleur system and requires much less maintenance due to the protection of the hub shell. Currently, the internal drive hub is becoming more and more popular as the transmission system of bicycles, especially for urban commuting. The most famous product is a 3-speed internal drive hub manufactured by the Sturmey-Archer Company [1]; it was designed more than 100 years ago. Internal drive hubs for bicycles are now offered in $5,7,8,11,12$ and 14 speed models [2-6]. The main body of an internal drive hub is a set of planetary gear mechanisms used to provide several forward speeds. Mechanical efficiency is an important index to evaluate the performance of a bicycle's internal drive hub. Unfortunately, the manufacturer usually treats the performance data as a trade secret, and it is difficult for customers to obtain the related information. Academic studies regarding the structural design [7-9] and kinematic analysis $[10,11]$ of internal drive hubs were proposed over the past few years. In contrast, the evaluation of mechanical efficiency of an internal drive hub has received relatively little attention. The systematic analysis process for guiding mechanical engineers to calculate the mechanical efficiency of a bicycle internal drive hub is still not available. In this study, the analytical process for determining the mechanical efficiency of internal drive hubs is introduced. An existing 14-speed internal drive hub is taken as an example to illustrate the analytical process and the mechanical efficiency of the internal drive hub at each speed is calculated.

\section{An Existing 14-Speed Internal Drive Hub}

Figure 1(a) shows an existing 14-speed internal drive hub produced by Rohloff AG Company [6]. The schematic diagram of this drive hub is sketched as shown in Figure 1(b), which is basically comprised of three sets of compound planetary gear trains I, II and III. It is a thirteen-link, four-degrees of freedom (DOF) gear mechanism. Link 0 is a stationary hub shaft. Links 1, 2, 3 and 4 are sun gears. Link 5 is a sun gear integrated with a ring gear. Links 6, 7 and 8 are compound planet gears. Links 9 and 10 are ring gears. Links 11 and 12 are carriers. Clutches a, b, c, d and e are locking clutches used to lock the related sun gears to the stationary hub shaft. Clutches A, B, C and D are one-way clutches used to transmit power to adjacent links. Table 1 is the clutching sequence table that indicates the engagement of each clutch at each gear. The symbol "O" represents the related clutch engaged at the related gear. 


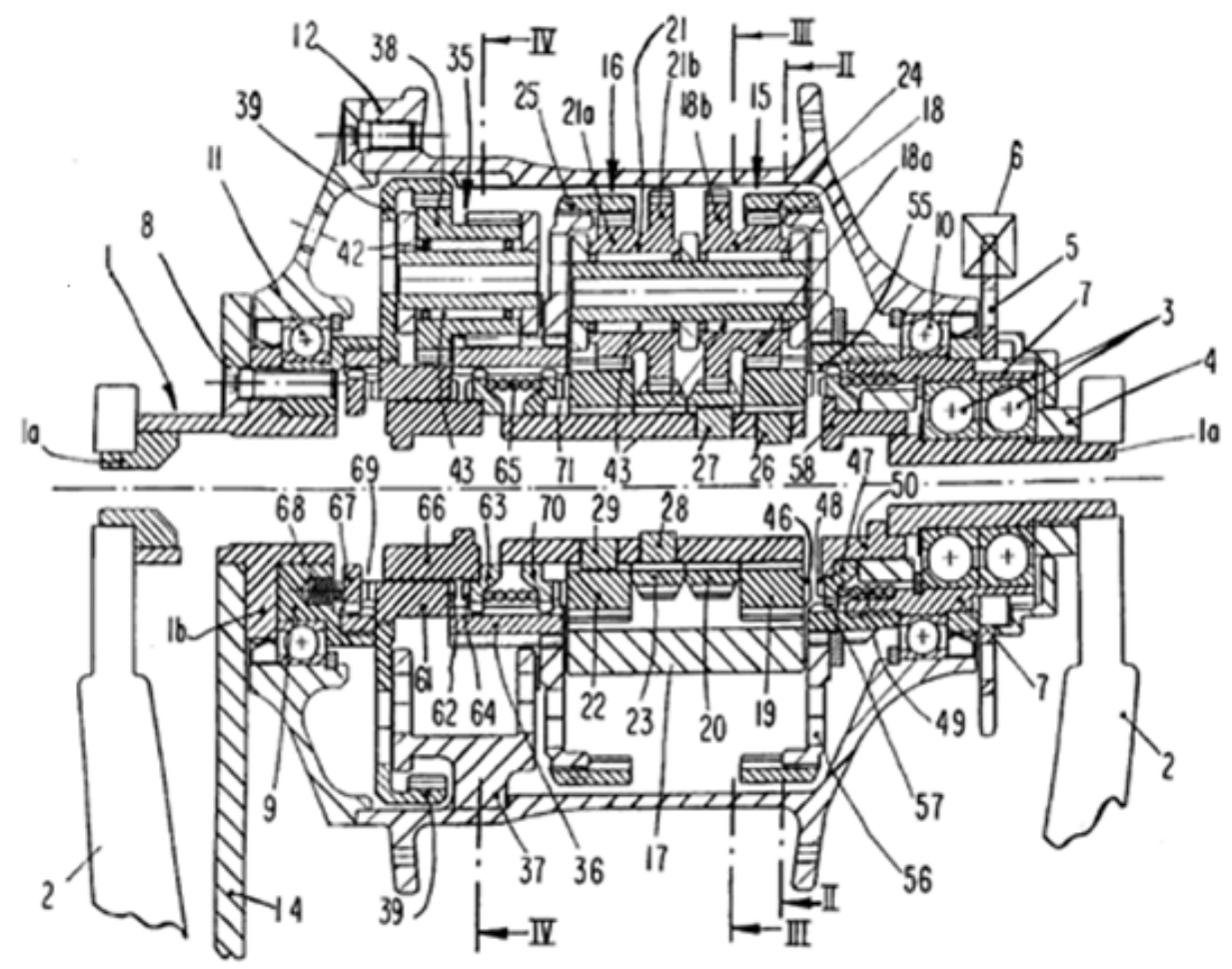

(a)cross-sectional view

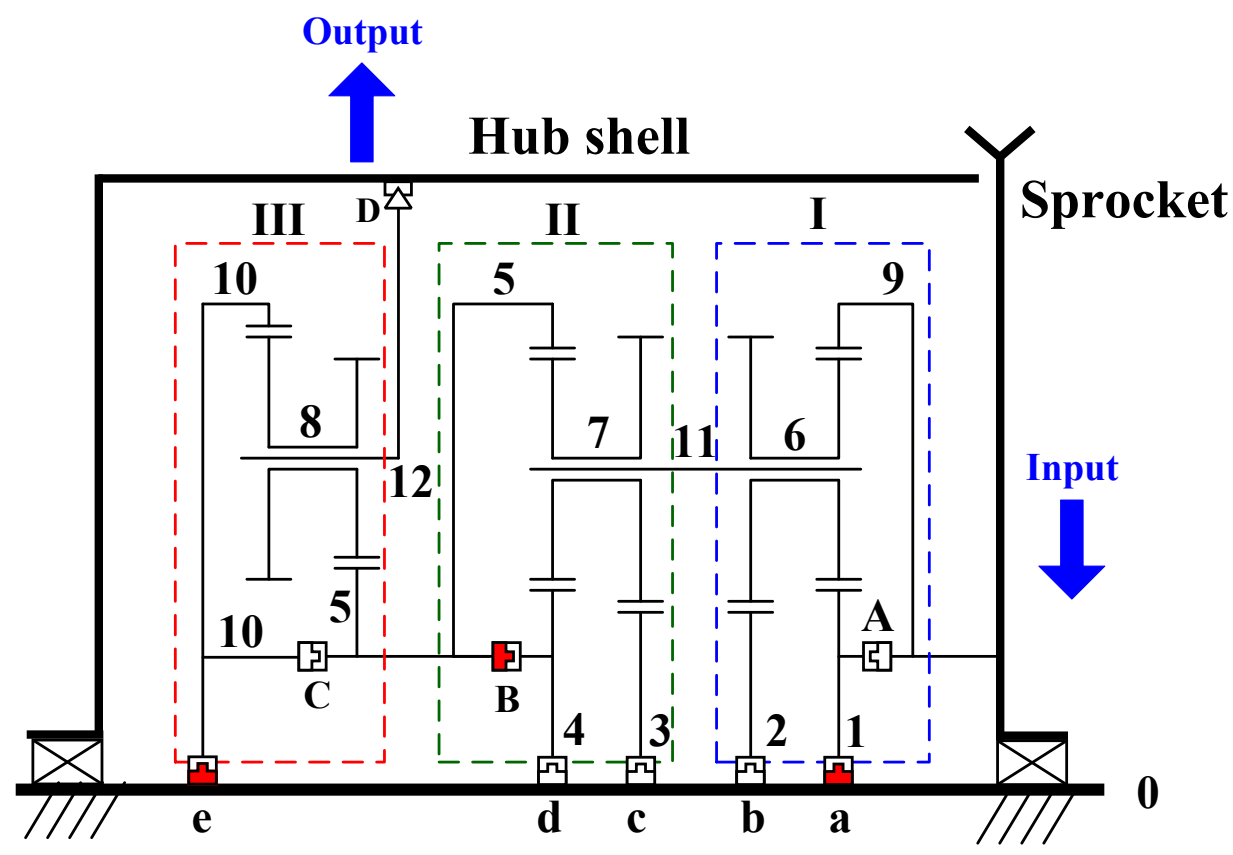

(b) schematic diagram

Figure 1. A 14-speed bicycle internal drive hub [6] 
Table 1. A clutching sequence table for the internal drive hub shown in Figure 1

\begin{tabular}{|l|l|l|l|l|l|l|l|l|l|}
\hline Clutch & $\mathrm{a}$ & $\mathrm{b}$ & $\mathrm{c}$ & $\mathrm{d}$ & $\mathrm{e}$ & $\mathrm{A}$ & $\mathrm{B}$ & $\mathrm{C}$ & $\mathrm{D}$ \\
\hline \hline Gear 1 & $\circ$ & & & & $\circ$ & & $\circ$ & & $\circ$ \\
\hline Gear 2 & & $\circ$ & & & $\circ$ & & $\circ$ & & $\circ$ \\
\hline Gear 3 & $\circ$ & & $\circ$ & & $\circ$ & & & & $\circ$ \\
\hline Gear 4 & & & & & $\circ$ & $\circ$ & $\circ$ & & $\circ$ \\
\hline Gear 5 & & $\circ$ & $\circ$ & & $\circ$ & & & & $\circ$ \\
\hline Gear 6 & & & $\circ$ & & $\circ$ & $\circ$ & & & $\circ$ \\
\hline Gear 7 & & & & $\circ$ & $\circ$ & & & & $\circ$ \\
\hline Gear 8 & $\circ$ & & & & & & $\circ$ & $\circ$ & $\circ$ \\
\hline Gear 9 & & $\circ$ & & & & & $\circ$ & $\circ$ & $\circ$ \\
\hline Gear 10 & $\circ$ & & $\circ$ & & & & & $\circ$ & $\circ$ \\
\hline Gear 11 & & & & & & $\circ$ & $\circ$ & $\circ$ & $\circ$ \\
\hline Gear 12 & & $\circ$ & & $\circ$ & & & & $\circ$ & $\circ$ \\
\hline Gear 13 & & & $\circ$ & & & $\circ$ & & $\circ$ & $\circ$ \\
\hline Gear 14 & & & & $\circ$ & & $\circ$ & & $\circ$ & $\circ$ \\
\hline
\end{tabular}

\section{Kinematic Analysis}

Kinematic analysis is a precursory step in efficiency analysis of a planetary gear mechanism. The fundamental circuit method [12] is applied to calculate the angular speed of each link of the planetary gear mechanism. Because there are eight gear pairs for the presented internal drive hub, eight fundamental circuits can be obtained: $(1,6) 11,(2,6) 11$, $(9,6) 11,(3,7) 11,(4,7) 11,(5,7) 11,(5,8) 12$ and $(10,8) 12$. The related fundamental circuit equations are listed as follows:

$$
\begin{aligned}
& \omega_{1}-\gamma_{6 / 1} \omega_{6}+\left(\gamma_{6 / 1}-1\right) \omega_{11}=0, \\
& \omega_{2}-\gamma_{6 / 2} \omega_{6}+\left(\gamma_{6 / 2}-1\right) \omega_{11}=0, \\
& \omega_{9}-\gamma_{6 / 9} \omega_{6}+\left(\gamma_{6 / 9}-1\right) \omega_{11}=0, \\
& \omega_{3}-\gamma_{7 / 3} \omega_{7}+\left(\gamma_{7 / 3}-1\right) \omega_{11}=0,
\end{aligned}
$$

$$
\begin{aligned}
& \omega_{4}-\gamma_{7 / 4} \omega_{7}+\left(\gamma_{7 / 4}-1\right) \omega_{11}=0, \\
& \omega_{5}-\gamma_{7 / 5} \omega_{7}+\left(\gamma_{7 / 5}-1\right) \omega_{11}=0, \\
& \omega_{5}-\gamma_{8 / 5} \omega_{8}+\left(\gamma_{8 / 5}-1\right) \omega_{12}=0, \\
& \omega_{10}-\gamma_{10 / 8} \omega_{8}+\left(\gamma_{10 / 8}-1\right) \omega_{12}=0,
\end{aligned}
$$

where $\omega_{\mathrm{i}}$ is the angular speed of link $i, \gamma_{\mathrm{j} / \mathrm{i}}= \pm \mathrm{Z}_{\mathrm{j}} / \mathrm{Z}_{\mathrm{i}}$ represents the gear ratio, and $Z_{i}$ is the number of teeth on gear $i$. The positive sign of the gear ratio is for an internal gear pair, and negative for an external gear pair. Table 2 presents the speed ratio formula and its value at each gear of the presented 14-speed drive hub. When the input angular speed of the sprocket is $1 \mathrm{rad} / \mathrm{sec}$, the angular speed of each link of the internal drive hub at each speed can be calculated based on Equations (1)-(8) and Table 2. Table 3 shows the related angular speeds. 
Table 2. The speed ratio of each speed of the presented 14-speed internal drive hub

\begin{tabular}{|c|c|c|c|c|c|}
\hline Gear & Fixed link & Input link & Output link & Speed ratio formula & Speed ratio \\
\hline Gear 1 & 1,10 & 9 & 12 & $\frac{\left(\gamma_{6 / 9}-\gamma_{6 / 1}\right)\left(\gamma_{8 / 10}-\gamma_{8 / 5}\right)}{\gamma_{6 / 1} \gamma_{8 / 10}}$ & 3.591 \\
\hline Gear 2 & 2,10 & 9 & 12 & $\frac{\left(\gamma_{6 / 9}-\gamma_{6 / 2}\right)\left(\gamma_{8 / 10}-\gamma_{8 / 5}\right)}{\gamma_{6 / 2} \gamma_{8 / 10}}$ & 3.163 \\
\hline Gear 3 & $1,3,10$ & 9 & 12 & $\begin{array}{l}\frac{-\left(\gamma_{6 / 9} \gamma_{7 / 3} \gamma_{8 / 10}-\gamma_{6 / 1} \gamma_{7 / 3} \gamma_{8 / 10}\right)}{\gamma_{6 / 1} \gamma_{7 / 5} \gamma_{8 / 10}-\gamma_{6 / 1} \gamma_{7 / 3} \gamma_{8 / 10}} \\
+\frac{-\left(-\gamma_{6 / 9} \gamma_{7 / 3} \gamma_{8 / 5}+\gamma_{6 / 1} \gamma_{7 / 3} \gamma_{8 / 5}\right)}{\gamma_{6 / 1} \gamma_{7 / 5} \gamma_{8 / 10}-\gamma_{6 / 1} \gamma_{7 / 3} \gamma_{8 / 10}}\end{array}$ & 2.779 \\
\hline Gear 4 & 10 & 9 & 12 & $\frac{\gamma_{8 / 5}-\gamma_{8 / 10}}{\gamma_{8 / 10}}$ & 2.448 \\
\hline Gear 5 & $2,4,10$ & 9 & 12 & $\begin{array}{l}\frac{-\left(\gamma_{6 / 9} \gamma_{7 / 4} \gamma_{8 / 10}-\gamma_{6 / 2} \gamma_{7 / 4} \gamma_{8 / 10}\right)}{\gamma_{6 / 2} \gamma_{7 / 5} \gamma_{8 / 10}-\gamma_{6 / 2} \gamma_{7 / 4} \gamma_{8 / 10}} \\
+\frac{-\left(-\gamma_{6 / 9} \gamma_{7 / 4} \gamma_{8 / 5}+\gamma_{6 / 2} \gamma_{7 / 4} \gamma_{8 / 5}\right)}{\gamma_{6 / 2} \gamma_{7 / 5} \gamma_{8 / 10}-\gamma_{6 / 2} \gamma_{7 / 4} \gamma_{8 / 10}}\end{array}$ & 2.157 \\
\hline Gear 6 & 3,10 & 9 & 12 & $\frac{\gamma_{7 / 3} \gamma_{8 / 10}-\gamma_{7 / 3} \gamma_{8 / 5}}{\gamma_{7 / 3} \gamma_{8 / 5}-\gamma_{7 / 3} \gamma_{8 / 10}}$ & 1.895 \\
\hline Gear 7 & 4,10 & 9 & 12 & $\frac{\gamma_{7 / 4} \gamma_{8 / 10}-\gamma_{7 / 4} \gamma_{8 / 5}}{\gamma_{7 / 4} \gamma_{8 / 5}-\gamma_{7 / 4} \gamma_{8 / 10}}$ & 1.670 \\
\hline Gear 8 & 1 & 9 & 12 & $\frac{\gamma_{6 / 9}-\gamma_{6 / 1}}{\gamma_{6 / 1}}$ & 1.467 \\
\hline Gear 9 & 2 & 9 & 12 & $\frac{\gamma_{6 / 9}-\gamma_{6 / 2}}{\gamma_{6 / 2}}$ & 1.292 \\
\hline Gear 10 & 1,3 & 9 & 12 & $\frac{\gamma_{7 / 4} \gamma_{8 / 10}-\gamma_{7 / 4} \gamma_{8 / 5}}{\gamma_{7 / 4} \gamma_{8 / 5}-\gamma_{7 / 4} \gamma_{8 / 10}}$ & 1.135 \\
\hline Gear 11 & -- & 9 & 12 & 1 & 1.000 \\
\hline Gear 12 & 2,4 & 9 & 12 & $\frac{-\left(\gamma_{6 / 9} \gamma_{7 / 3}-\gamma_{6 / 2} \gamma_{7 / 3}\right)}{\gamma_{6 / 2} \gamma_{7 / 5}-\gamma_{6 / 2} \gamma_{7 / 3}}$ & 0.881 \\
\hline Gear 13 & 3 & 9 & 12 & $\frac{\gamma_{7 / 3}}{\gamma_{7 / 5}-\gamma_{7 / 3}}$ & 0.774 \\
\hline Gear 14 & 4 & 9 & 12 & $\frac{\gamma_{7 / 4}}{\gamma_{7 / 5}-\gamma_{7 / 4}}$ & 0.682 \\
\hline \multicolumn{6}{|c|}{ Gear ratios } \\
\hline \multicolumn{6}{|c|}{$\begin{array}{l}\gamma_{6 \mathrm{a} / 1}=-0.571, \gamma_{6 \mathrm{~b} / 2}=-0.914, \gamma_{6 \mathrm{a} / 9}=0.267, \gamma_{7 \mathrm{~b} / 3}=-0.914 \\
\gamma_{7 \mathrm{a} / 4}=-0.571, \gamma_{7 \mathrm{a} / 5 \mathrm{r}}=0.267, \gamma_{8 \mathrm{a} / 5 \mathrm{~s}}=-0.392, \gamma_{8 \mathrm{~b} / 10}=0.271\end{array}$} \\
\hline
\end{tabular}


Table 3. The angular speed of each link of the drive hub at each speed (Unit: $\mathrm{rad} / \mathrm{sec}$ )

\begin{tabular}{|c|c|c|c|c|c|c|c|c|c|c|c|c|c|}
\hline $\begin{array}{l}\text { Link } \\
\text { Gear }\end{array}$ & 1 & 2 & 3 & 4 & 5 & 6 & 7 & 8 & 9 & 10 & 11 & 12 & $\begin{array}{l}\text { Speed } \\
\text { ratio }\end{array}$ \\
\hline Gear 1 & 0 & -0.409 & 0.681 & 0.681 & 0.681 & 1.875 & 0.681 & -0.749 & 1 & 0 & 0.681 & 0.279 & 3.584 \\
\hline Gear 2 & 0.290 & 0 & 0.774 & 0.774 & 0.774 & 1.621 & 0.774 & -0.851 & 1 & 0 & 0.774 & 0.316 & 3.165 \\
\hline Gear 3 & 0 & -0.409 & 0 & 0.256 & 0.880 & 1.875 & 1.427 & -0.968 & 1 & 0 & 0.981 & 0.360 & 2.778 \\
\hline Gear 4 & 1 & 1 & 1 & 1 & 1 & 1 & 1 & -1.100 & 1 & 0 & 1 & 0.409 & 2.445 \\
\hline Gear 5 & 0.290 & 0 & -0.465 & 0 & 1.136 & 1.621 & 2.129 & -1.249 & 1 & 0 & 0.774 & 0.464 & 2.155 \\
\hline Gear 6 & 1 & 1 & 0 & 0.375 & 1.292 & 1 & 2.094 & -1.421 & 1 & 0 & 1 & 0.528 & 1.894 \\
\hline Gear 7 & 1 & 1 & -0.601 & 0 & 1.468 & 1 & 2.751 & -1.314 & 1 & 0 & 1 & 0.599 & 1.669 \\
\hline Gear 8 & 0 & -0.409 & 0.681 & 0.681 & 0.681 & 1.875 & 0.681 & 0.681 & 1 & 0.681 & 0.681 & 0.681 & 1.468 \\
\hline Gear 9 & 0.290 & 0 & 0.774 & 0.774 & 0.774 & 1.621 & 0.774 & 0.774 & 1 & 0.774 & 0.774 & 0.774 & 1.292 \\
\hline Gear 10 & 0 & -0.409 & 0 & 0.256 & 0.880 & 1.875 & 1.427 & 0.880 & 1 & 0.880 & 0.681 & 0.880 & 1.25 \\
\hline Gear 11 & 1 & 1 & 1 & 1 & 1 & 1 & 1 & 1 & 1 & 1 & 1 & 1 & 1 \\
\hline Gear 12 & 0.290 & 0 & -0.465 & 0 & 1.136 & 1.621 & 2.129 & 1.136 & 1 & 1.136 & 0.774 & 1.136 & 0.880 \\
\hline Gear 13 & 1 & 1 & 0 & 0.375 & 1.292 & 1 & 2.094 & 1.292 & 1 & 1.292 & 1 & 1.292 & 0.773 \\
\hline Gear 14 & 1 & 1 & -0.601 & 0 & 1.468 & 1 & 2.751 & 1.468 & 1 & 1.468 & 1 & 1.468 & 0.681 \\
\hline
\end{tabular}

Table 4. The ideal static torque of each link of the drive hub at Gear 1 (Unit: Nm)

\begin{tabular}{|c|c|c|c|c|c|}
\hline $\begin{array}{c}\text { Fundamental circuit } \\
\text { Link }\end{array}$ & $(1,6) 11$ & $(9,6) 11$ & $(5,8) 12$ & $(10,8) 12$ & $\begin{array}{c}\text { Ideal static } \\
\text { torque }\end{array}$ \\
\hline 1 & 0.468 & -- & -- & -- & 0.468 \\
\hline 5 & -0.735 & -0.733 & 1.468 & -- & 0 \\
\hline 6 & 0.267 & -0.267 & -- & -- & 0 \\
\hline 8 & -- & -- & 0.576 & -0.576 & 0 \\
\hline 9 & -- & 1.000 & -- & -- & 1.000 \\
\hline 10 & -- & -- & -- & 2.125 & 2.125 \\
\hline 11 & -0.735 & -0.733 & 1.468 & -- & 0 \\
\hline 12 & -- & -- & -2.043 & -1.549 & -3.592 \\
\hline
\end{tabular}




\section{Static Torque Analysis}

For each fundamental circuit, the corresponding basic equations for static torques can be listed. We take Gear 1 of the internal drive hub as an example to explain. Fifteen basic equations for ideal static torques in this gear mechanism are listed as follows:

$$
\begin{gathered}
\mathrm{T}_{1}^{1}+\gamma_{1 / 6} \mathrm{~T}_{6}^{1}=0, \\
\mathrm{~T}_{9}^{3}+\gamma_{9 / 6} \mathrm{~T}_{6}^{3}=0, \\
\mathrm{~T}_{5}^{7}+\gamma_{5 / 8} \mathrm{~T}_{8}^{7}=0, \\
\mathrm{~T}_{10}^{8}+\gamma_{10 / 8} \mathrm{~T}_{8}^{8}=0, \\
\mathrm{~T}_{1}^{1}+\mathrm{T}_{6}^{1}+\mathrm{T}_{11}^{1}=0, \\
\mathrm{~T}_{9}^{3}+\mathrm{T}_{6}^{3}+\mathrm{T}_{11}^{3}=0, \\
\mathrm{~T}_{5}^{7}+\mathrm{T}_{8}^{7}+\mathrm{T}_{12}^{7}=0, \\
\mathrm{~T}_{10}^{8}+\mathrm{T}_{8}^{8}+\mathrm{T}_{12}^{8}=0, \\
\mathrm{~T}_{1}=\mathrm{T}_{1}^{1}, \\
\mathrm{~T}_{6}=\mathrm{T}_{6}^{1}+\mathrm{T}_{6}^{3}=0, \\
\mathrm{~T}_{8}=\mathrm{T}_{8}^{7}+\mathrm{T}_{8}^{8}=0, \\
\mathrm{~T}_{9}=\mathrm{T}_{9}^{3}=1 \mathrm{Nm}, \\
\mathrm{T}_{10}=\mathrm{T}_{10}^{8}, \\
\mathrm{~T}_{11}=\mathrm{T}_{11}^{1}+\mathrm{T}_{11}^{3}+\mathrm{T}_{5}^{7}=\mathrm{T}_{5}^{7}, \\
\mathrm{~T}_{12}^{8}, \\
\end{gathered}
$$

When the input static torque of the sprocket is $1 \mathrm{Nm}$, i.e. $\mathrm{T}_{9}=1 \mathrm{Nm}$, the ideal static torque for each link at Gear 1 can be calculated by solving the above equations. The numerical results of ideal torque analysis are presented in Table 4.

By further considering the gear-mesh loss to each gear pair, Equations (9)-(12) are modified as follows [13]:

$$
\begin{gathered}
\mathrm{T}_{1}^{1}+\gamma_{1 / 6}\left(\eta_{1 / 6}^{\mathrm{c}}\right) \mathrm{T}_{6}^{1}=0, \\
\mathrm{~T}_{9}^{3}+\gamma_{9 / 6}\left(\eta_{9 / 6}^{\mathrm{c}}\right) \mathrm{T}_{6}^{3}=0, \\
\mathrm{~T}_{5}^{7}+\gamma_{5 / 8}\left(\eta_{5 / 8}^{\mathrm{c}}\right) \mathrm{T}_{8}^{7}=0, \\
\mathrm{~T}_{10}^{8}+\gamma_{10 / 8}\left(\eta_{10 / 8}^{\mathrm{c}}\right) \mathrm{T}_{8}^{8}=0,
\end{gathered}
$$

The symbol $\eta$ represents the efficiency of a gear pair. In this drive hub, the efficiency of an external gear pair is assumed to be $98 \%$, while the efficiency of an internal gear pair is assumed to be $99 \%$ [13], i.e. $\eta_{1 / 6}=\eta_{5 / 8}=0.98$ and $\eta_{9 / 6}=\eta_{10 / 8}=0.99$. By solving Equations (13)-(27), the actual static torque of each link at Gear 1 is listed in Table 5.

\section{Power-flow Diagram}

Since the power is equal to the product of the actual static torque and the angular speed, the transmitted power at each link can be obtained based on the analysis results of kinematic analysis and static torque analysis shown in Tables 3 and 5. Table 6 shows the transmitted power at each link in the related fundamental circuits and links of the internal drive hub at Gear 1, while Figure 2 presents the related power-flow diagram.

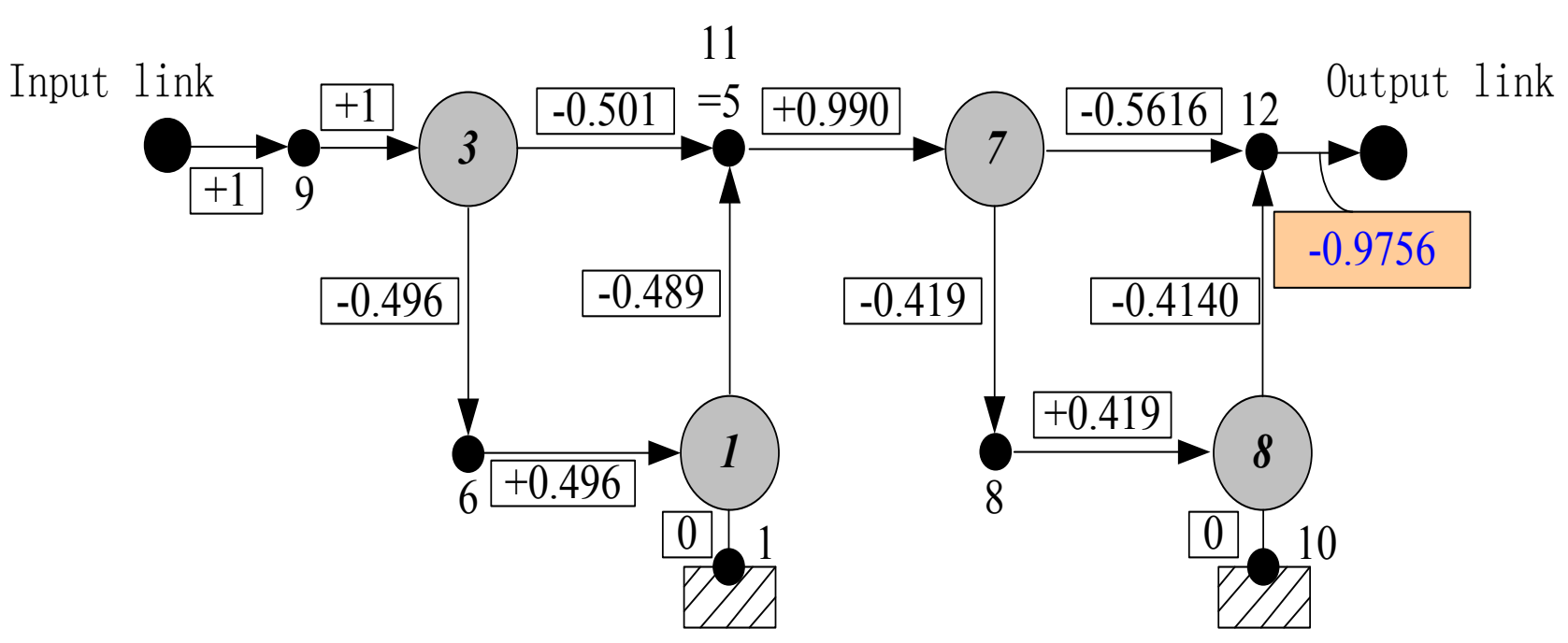

Figure 2. The power-flow diagram of the presented internal drive hub at Gear 1 
Table 5. The actual static torque of each link of the drive hub at Gear 1 (Unit: Nm)

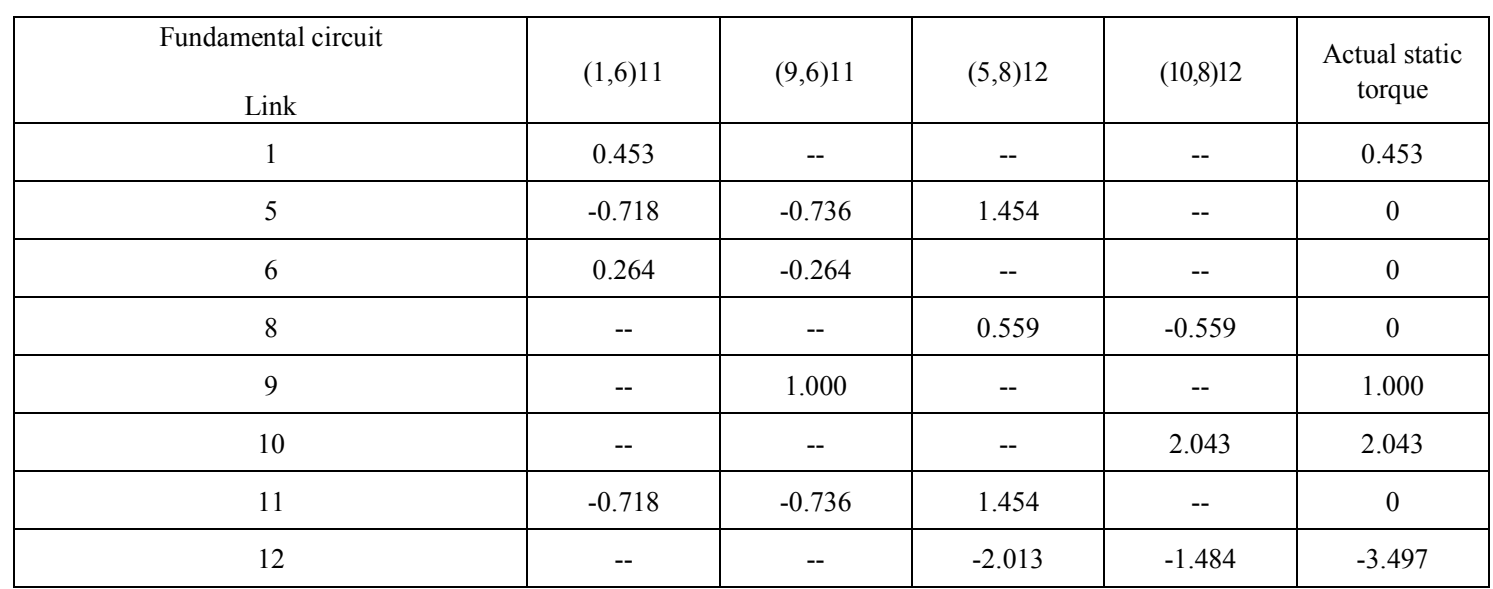

Table 6. The transmitted power at each link in the related fundamental circuits of the internal drive hub at Gear 1 (Unit: W)

\begin{tabular}{|c|c|c|c|c|c|}
\hline $\begin{array}{c}\text { Fundamental circuit } \\
\text { Link }\end{array}$ & $(1,6) 11$ & $(9,6) 11$ & $(5,8) 12$ & $(10,8) 12$ & Transmitted power \\
\hline 1 & 0 & -- & -- & -- & -- \\
\hline 5 & -0.489 & -0.501 & 0.990 & -- & 0 \\
\hline 6 & 0.495 & -0.495 & -- & 0.419 & -0 \\
\hline 8 & -- & -- & -0.419 & -- & 0 \\
\hline 9 & -- & 1.000 & -- & 0 \\
\hline 10 & -0.489 & -0.501 & 0.990 & - & 0 \\
\hline 11 & -- & - & -0.5616 & -0.4140 & -0.9756 \\
\hline
\end{tabular}

Table 7. Mechanical efficiency of the drive hub at each gear

\begin{tabular}{|c|c|}
\hline Gear & Mechanical efficiency $(\%)$ \\
\hline Gear 1 & 97.56 \\
\hline Gear 2 & 97.55 \\
\hline Gear 3 & 96.77 \\
\hline Gear 4 & 98.36 \\
\hline Gear 5 & 97.11 \\
\hline Gear 6 & 97.63 \\
\hline Gear 7 & 97.22 \\
\hline Gear 8 & 99.02 \\
\hline Gear 9 & 99.30 \\
\hline Gear 10 & 98.29 \\
\hline Gear 11 & 100.00 \\
\hline Gear 12 & 98.37 \\
\hline Gear 13 & 99.23 \\
\hline Gear 14 & 99.08 \\
\hline
\end{tabular}




\section{Mechanical Efficiency Analysis}

The mechanical efficiency of a gear mechanism is equal to the ratio of the output power to the input power. Since the input power and output power of the internal drive hub at Gear 1 are $1 \mathrm{~W}$ and $0.9756 \mathrm{~W}$, respectively, the mechanical efficiency of this drive hub at Gear 1 is $97.56 \%$. Table 7 shows the mechanical efficiency of the drive hub at each gear. It is interesting to find that the existing 14-speed internal drive hub possesses high mechanical efficiency at each gear. This is a significant advantage for bicycle internal drive hubs composed of planetary gear mechanisms.

\section{Conclusions}

In this study, an analytical method for predicting the mechanical efficiency of an existing internal drive hub is presented based on the fundamental circuit method. When the power flow goes through compound planetary gear trains I, II and III simultaneously, i.e. Gears 3 and 5, the mechanical efficiencies at these two gears are lower than at other gears. This is because the power flow going through three sets of planetary gear train suffers from more gear-mesh losses, and hence reduces the output transmitted power and mechanical efficiency. The proposed analytical process can be used on other internal drive hubs composed of planetary gear mechanisms.

\section{Acknowledgements}

The authors are grateful for the financial support of this research from the Ministry of Science and Technology (Taiwan, R.O.C.) under Grant No. 102-2221-E-224-016-M Y2.

\section{REFERENCES}

[1] Sturmey Archer Co. http://www.sturmey-archer.com/products/hubs/cid/3.html, 2014.

[2] Hillyer, A. W., Epicyclic change speed hub. U. S. Patent No. $3,886,811,1975$.

[3] Nagano, M., Self-contained change speed apparatus with shaped pawls to equalize a shifting spring force for a bicycle. U. S. Patent No. 5,322,487, 1993.

[4] Meier-Burkamp, G., Multi-speed hub for bicycles. U. S. Patent No. 5,527,230, 1996.

[5] Hino, T., Bicycle hub transmission. U. S. Patent No. 7,967,718, 2011.

[6] Bernhard, R., Multispeed Bicycle Gear System. U. S. Patent No. 6258005, 2001.

[7] Hsu, C. H., Wen, T. C., Creative Design Methodology for Split-Power Multi-Speed Drive Hubs of Bicycles (in Chinese), Proceedings of the $11^{\text {th }}$ National Conference on the Design of Mechanisms and Machines, Hsinchu, Taiwan, 2008, Paper No. A1N-51943: 1-6.

[8] Hsieh, L. C., Chen, T. H., The Innovative and Engineering Design of Six-speed Gear hub System for a Bicycle (in Chinese), Proceedings of the $9^{\text {th }}$ National Conference on the Design of Mechanisms and Machines, Kaohsiung, Taiwan, 2006, 351-358.

[9] Chen, L. A., Ren, P. W., Wu, Y. C., Design of a Gear-Shifting Control Mechanism for 8-Speed Bicycle Drive Hubs, Smart Science, 2013, 1(2): 94-98.

[10] Wu, Y. C., Sun, Z. H., Design and Analysis of a Novel Speed-Changing Wheel Hub with an Integrated Electric Motor for Electric Bicycles, Mathematical Problems in Engineering, 2013, Article ID 369504: 1-8.

[11] Wu, Y. C., Ren, P. W., Chen, L. A., Kinematic Analysis of an 8-Speed Bicycle Transmission Hub, Applied Mechanics and Materials, 2014, Vols. 479-480: 234-238.

[12] Tsai, L. W., Mechanism Design: Enumeration of Kinematic Structures According to Function, CRC Press LLC, 2001.

[13] Wu, Y. C., Cheng, C. H., Computing the Power Flow and Mechanical Efficiency of In-Hub Bicycle Transmissions, Engineering Computations, 2014, 31(2): 267-282. 